\title{
Burden of informal caregivers of dependent elderlies in the community in small cities
}

\author{
Sobrecarga de cuidadores informais de idosos dependentes \\ na comunidade em municípios de pequeno porte \\ Sobrecarga de cuidadores informales de ancianos dependientes \\ en la comunidad en municipios de pequeño porte \\ Marines Aires ${ }^{\mathrm{a}}$ \\ Ana Cláudia Fuhrmann ${ }^{b}$ \\ Duane Mocellinc \\ Fernanda Laís Fengler Dal Pizzol ${ }^{\mathrm{d}}$ \\ Laura Franco Sponchiado ${ }^{a}$ \\ Carla Regina Marchezan ${ }^{a}$ \\ Carla Cristiane Becker Kottwitz Bierhals ${ }^{\mathrm{b}}$ \\ Carolina Baltar Daye \\ Naiana Oliveira dos Santos ${ }^{f}$ \\ Lisiane Manganelli Girardi Paskulin ${ }^{\mathrm{b}}$
}

\begin{abstract}
How to cite this article: Aires M, Fuhrmann AC, Mocellin D, Dal Pizzol FLF, Sponchiado LF, Marchezan CR, Bierhals CCBK, Day CB, Santos NO, Paskulin LMG. Burden of informal caregivers of dependent elderlies in the community in small cities. Rev Gaúcha Enferm. 2020:41(esp):e20190156 doi: https://doi.org/10.1590/19831447.2020.20190156
\end{abstract}

a Universidade Regional Integrada do Alto Uruguai e das Missões (URI). Frederico Westphalen, Rio Grande do Sul, Brasil.

- Universidade Federal do Rio Grande do Sul, Escola de Enfermagem, Programa de Pós-Graduaçăoem Enfermagem. Porto Alegre, Rio Grande do Sul, Brasil.

Grupo Hospitalar Conceição (GHC), Residência Multiprofissional em Saúde, Porto Alegre, Rio Grande do Sul, Brasil.

d Unimed Porto Alegre, Porto Alegre, Rio Grande do Sul, Brasil.

e Pontifícia Universidade Católica do Rio Grande do Sul (PUCRS). Rio Grande do Sul, Brasil.

Universidade Franciscana (UFN), Santa Maria, Rio Grande do Sul, Brasil.

\section{ABSTRACT}

Aim: To analyze sociodemographic factors and aspects of care related to the burden of informal caregivers of dependent elderlies in the community.

Methods: A cross-sectional study with 125 caregivers. Data collection was carried out in municipalities of the Northwest of Rio Grande do Sul through a structured interview in 2017 and 2018. The Caregiver Burden Inventory was used. The Pearson or Spearman correlation coefficients and t-student test or Analysis of Variance (ANOVA) were done. For the multivariate analysis, Linear Regression was used. Results: Most caregivers were female (73.6\%), married (55.2\%) and daughters (68.0\%). The variables that showed a statistically significant relationship with burden were: caregiver age $(p=0.039)$, education $(p=0.001)$, time devoted to care $(p=<0.001)$, kinship degree $(p=0.001)$, living with the elder $(p<0.001)$, using their income $(p=0.001)$ and female gender $(p=0.017)$.

Conclusion:Women caregivers, with less education, who spend more time in weekly care and lived with the elder presented higher burden. Keywords: Caregivers. Aged. Nursing. Primary Health Care.

\section{RESUMO}

Objetivo: Analisar os fatores sociodemográficos e aspectos do cuidado relacionados à sobrecarga dos cuidadores informais de idosos dependentes na comunidade.

Métodos: Estudo transversal, com 125 cuidadores informais de idosos dependentes, realizado em 2017 e 2018, em municípios do Noroeste do Estado do Rio Grande do Sul, mediante entrevista. Utilizou-se o Inventário de Sobrecarga do Cuidador. Na análise bivariada, utilizaram-se os coeficientes de correlação de Pearson ou Spearman e teste t-Student, ou Análise de Variância (ANOVA) e Tukey. Na análise multivariada, utilizou-se a Regressão Linear.

Resultados: Predominaram cuidadoras (73,6\%), casadas (55,2\%) e filhas (68,0\%). As variáveis que apresentaram relação estatisticamente significativa com a sobrecarga foram: idade do cuidador $(p=0,039)$, escolaridade ( $p=0,001)$, tempo dedicado ao cuidado $(p=<0,001)$, grau de parentesco $(p=0,001)$, residir com idoso $(p<0,001)$, utilizar a sua renda $(p=0,001)$ e sexo feminino $(p=0,017)$. Conclusão: Cuidadoras mulheres, com menor escolaridade, que dispensavam maior tempo de cuidado semanal e residiam com 0 idoso apresentaram maior sobrecarga.

Palavras-chave: Cuidadores. Idoso. Enfermagem. Atenção Primária à Saúde.

RESUMEN

Objetivo: Analizar los factores sociodemográficos y aspectos del cuidado relacionados a la sobrecarga de los cuidadores informales de ancianos dependientes en la comunidad.

Métodos: Estudio transversal con 125 cuidadores informales de ancianos dependientes. La colecta de datos fue realizada en 2017 y 2018 en municipios del Noroeste del Estado de Rio Grande do Sul, Brasil, por medio de entrevista estructurada. Se utilizó el Inventario de Sobrecarga del Cuidador. En el análisis bivariado se utilizó los coeficientes de correlación de Pearson o Spearman y el teste t de Student 0 Análisis de Varianza (ANOVA) complementado por Tukey. Para el análisis multivariante se utilizó la Regresión Linear.

Resultados: Han predominado cuidadoras $(73,6 \%)$, casadas $(55,2 \%)$ e hijas $(68,0 \%)$. Variables que presentan relación estadísticamente significativa con la sobrecarga: edad del cuidador $(p=0,039)$, escolaridad $(p=0,001)$, tiempo dedicado al cuidado del anciano $(p=<0,001)$ grado de parentesco $(p=0,001)$, vivir con el anciano $(p<0,001)$, utilizar su renta para los gastos con el anciano $(p=0,001)$ sexo femenino $(p=0,017)$.

Conclusión: Cuidadores del sexo femenino, con menor escolaridad, que dispensan mayor tiempo de cuidado semanal y viven con el anciano presentan mayor sobrecarga.

Palabras clave: Cuidadores. Anciano. Enfermería. Atención Primaria de Salud. 


\section{口INTRODUCTION}

The experience of being the caregiver of an elder is increasingly frequent, since the incidence of chronic diseases and the number of dependent elderlies grows as the population ages ${ }^{(1)}$. Considering that this is the Brazilian population profile, a discussion has been raised with regards to the number of specialized services necessary to attend this population, especially in the cities in the countryside of Brazil, in which the few services available are frequently unprepared to deal with the demands of the aging population.

In addition, the demographic and epidemiological transition is not evenly distributed in the different countries and socioeconomic contexts. In Brazil, this process took place fast, in a context of social and cultural inequalities, and heterogeneously, in the different cities of the country. Also, despite this setting, the predominant model is targeted at spontaneous demand, with an insufficient formal support network and changes in family structure ${ }^{(1-3)}$.

It also stands out that the elderly population uses health services more frequently, being hospitalized more often and for longer than other age groups. In general, elderlies need caregivers at all moments, permanent care, continuous medication, and periodical exams $\mathrm{s}^{(2-3)}$.

In this setting, the care offered to the elder who depends on others is constantly offered by their families, friends and/or neighbors ${ }^{(1,4)}$, at home, people often have little training and knowledge to offer adequate care, something that, added to the insufficiency of the formal support network, may lead to healthcare burden or make it worse $\mathrm{e}^{(5)}$.

Burden is the impact of the changes in the subject over the family and the resulting need for care and supervision(6). International studies identified factors that predispose to burden, such as: being a female caregiver, being of old age, being a widower, offering emotional support, spending many hours offering care, having little knowledge on activities of care $^{(7-8)}$. Similarly, national studies have found that having little training to offer care and offering care during many hours or throughout the entire day are predictive factors for burden ${ }^{(9-10)}$.

Brazilian studies found factors that contribute for burden that were not accounted for in international studies, such as: living with the elder, having a lower educational level, little formal and informal support, low family income, and being the romantic partner of the person receiving care. Other factors that predispose caregivers to become overloaded include occupying multiple roles, offering financial support, and aiding in basic Activities of Daily Living (ADL), such as bathing, dressing and eating ${ }^{(9-12)}$, not to mention that the burden resulting from the process of caring for a dependent elder can lead to psychiatric symptoms, fatigue, as well as to acute and chronic diseases ${ }^{(13-15)}$.

It should be highlighted that the national studies were developed in large urban centers or were linked to attention services that cared exclusively for elderlies, or to house attention programs. This shows that studies in small-sized cities, which only receive support from the Family Health Teams in the context of Primary Health Care (PHC) are incipient.

Therefore, the development of studies in small-sized municipalities that analyze the relation of sociodemographic factors with aspects of healthcare, such as burden, makes it possible to identify which of these factors cause the greater impact in caregiver burden, considering socioeconomic and cultural aspects of cities in the countryside of the state of Rio Grande do Sul (RS). These characteristics make up multivariate analysis in national and international studies on the subject.

Therefore, identifying the burden of informal caregivers of depending elderly in cities from the countryside of the state of RS will enable efficient interventions in the context of PHC, aiming to improve the quality of the care offered to the elder, as well as reducing the burden of informal caregivers. Additionally, it may offer support to professionals to structure the healthcare pathways for this group of the population, focusing on health promotion and prevention, to avoid the burden of these caregivers.

Considering this, the objective of this study was analyzing the sociodemographic features and aspects of healthcare, as related to the burden of informal caregivers of depending elderlies in the community.

\section{METHODS}

This is an analytical cross-sectional study. The investigation was carried out in the Health Units with Family Health Strategies (FHS) from five cities within the scope of the 19th Regional Health Administration (RHA) from the Northwest Region of the RS State, a total of 12 units.

The cities were chosen as they were connected to the teaching institution, being a field for the formation of students, while also being small-sized cities whose populations were clearly aging. According to data from the Brazilian Institute of Geography and Statistics (Instituto Brasileiro de Geografia e Estatística - IBGE) ${ }^{(16)}$, the 26 cities that make up the 19th RHA have a total of 187.063 people. From these, 28.841 are elderlies, a total of $15.41 \%$.

The participants from the study were people who referred to themselves as caregivers, each of an individual with 60 years of age or more, who was dependent on others to carry 
out one or more ADLs (which was verified using a list of dependent patients from a FHS unit), who lived in the area of coverage of the unit or were registered in the health unit. Minors were excluded.

The sample was calculated using the software in WinPEPI (Programs for Epidemiologists for Windows), version 11.43, and based on the study by Aires et. al ${ }^{(11)}$. Considering a significance level of $5 \%$, a statistical power of $90 \%$, a minimal correlation coefficient of 0.3 between the burden scale and the sociodemographic variables and aspects of care, a standard deviation of burden estimated in 2.3 points and minimum effect size of 0.6 standard deviations, the minimum total of participants calculated was 125 .

Patients were found through: the use of the Information System e-SUS, indications from Community Health Agents, lists of patients in health units, and through active search by the research team in the units. Caregivers were invited to participate in the study via telephone, and interviews were scheduled according to their availability.

The Caregiver Burden Inventory, adapted and validated for use in Brazil, was used to evaluate the burden of caregivers ${ }^{(17)}$. Cronbach's alpha values in the scale varied from 0.753 to 0.919 , with domains 2 and 3 (physical and emotional burden) with the highest values. The results of the analysis of the confirming factor were: Root Mean Square Error of Approximation $=0.065$; Comparative Fit Index $=0.935$ and Parsimony Comparative Index $=0.645^{(17)}$.

The instrument has 24 questions divided in five domains. Domain 1 evaluates the burden as related to time and how much help the elder needs in their daily activities. Domain 2 identifies burden related to personal life (if the time spent aiding the elder negatively reflects on personal life). Domain 3 relates physical burden to mental and physical health. Domain 4 measures social burden, that is, evaluates the feelings of family conflict and problems that involve the activity of offering care. Finally, domain 5 identifies emotional burden, describing negative feelings as related to the person who receives care.

Each question receives a score from 0 (completely disagree) to 4 (completely agree). Each domain has five questions, except the Physical Burden domain, which has four, which means its result must be multiplied by 1.25 . The score for each domain varies from 0 to 20 , and the total score of the scale is 100 . The instrument has no cut off point to classify burden. The highest the score, the highest the burden of the caregiver is. However, it is possible to verify both the scores of each dimension and the global score of the instrument.

Another instrument was used, containing sociodemographic variables: sex, age, marital status, and caregiver age. This instrument also collected data related to the relation of care: kinship degree, whether the caregiver lives with the elderly, for how long has they been caring for this elder, if there is someone else to care for the elderly, and if their income is used to cover the expenses of the elder. Regarding the elder, the variables were: sex, age, and income.

Data collection was carried out in the house of the participants by a team trained to do so from August 2017 and July 2018. The outcome was the total burden score, which was related to the variables mentioned. The software Statistical Package for the Social Sciences (SPSS), version 21.0, was used to analyze data, including descriptive, bivariate, and multivariate analysis.

To verify the normality of the variables, the Shapiro-Wilk test was used. Quantitative variables were described using means and standard deviation, or medians and interquartile range. The categorical variables were described according to absolute and relative frequencies. Regarding the domains of the Caregiver Burden Inventory, the distribution of variables was asymmetric, and so, the median value was used to compare them. The mean was used in the sum of the total score of the scale, from all domains.

For the bivariate analysis, Pearson product-moment correlation coefficient, or Spearman's correlation were used, as well as Student's t test or Variance Analysis (ANOVA), complemented by Tukey. The variables that presented $\mathrm{p}$-value $<0.20$ in bivariate analysis were inserted in the multivariate model, with the application of Linear Regression. A significance level of $5 \%(p<0.05)$ was applied. The project was approved by the Research Ethics Committee ( $n^{\circ}$ 1.457.332).

\section{Q RESULTS}

Regarding the characteristics of participants of the study, most caregivers were female, married/living with a partner and children. Table 1 presents the sociodemographic characteristics of the informal caregivers.

Regarding the burden of caregivers, Table 2 presents the burden scores according to the Caregiver Burden Inventory. There was a greater burden in the domain "Time-Dependence Burden". The mean score of all domains was $41.6 \pm 18.8$. 
Aires M, Fuhrmann AC, Mocellin D, Dal Pizzol FLF, Sponchiado LF, Marchezan CR, Bierhals CCBK, Day CB, Santos N0, Paskulin LMG

Table 1 - Characteristics of informal caregivers of dependent elderlies. Northwest Region, RS, Brazil, 2019

\section{Variables}

Age of the caregiver*

Sex of the caretgiver **

Male

Female

Educational level (years)*

Marital status **

Single or never married

Married/living with a partner

Widower

Divorced

Relationship **

Children

Partner

Grandchildren

Siblings

Others

The caregiver lives with the elderly**

Yes

How long has the caregiver being caring for the elderly (years) *

Age of the elderly (years) *

Has aid from someone else to offer care **

Yes

Length of time the caregiver devotes to care for the elderly (hr/week) *

Length of time others devote to care for the elder (hr/week) *

The elderly has their own income ${ }^{* *}$

Yes

What is the elderly's income **

1 to 2 minimum wages

2 to $3 \mathrm{~m} . \mathrm{w}$.

3 to $5 \mathrm{~m}$. w.

$>5$ m.w.

The caregiver must spend their own income to cover expenses with the elder**

No

Someone else helps financially to care for this elderly**

No

Source: Research Data, 2019

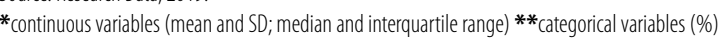


Table 2 - Caregiver Burden according to the domains in the Caregiver Burden Inventory. Northeast Region, RS, Brazil, 2019

\begin{tabular}{lccc} 
Domains & Mean \pm SD & Median (P25-P75) & Min. - Max. \\
Time-Dependence Burden & $\mathbf{1 1 . 6} \pm \mathbf{5 . 1 2}$ & $11(7-16)$ & $0-20$ \\
\hline Developmental Burden & $9.66 \pm 5.75$ & $9(5-15)$ & $0-20$ \\
\hline Physical Burden & $8.13 \pm 5.37$ & $6.3(5-12.5)$ & $0-20$ \\
\hline Social Burden & $7.31 \pm 3.75$ & $5(5-10)$ & $0-19$ \\
\hline Emotional Burden & $4.94 \pm 3.51$ & $40(27.8-55.5)$ & $0-20$ \\
\hline Total Score & $41.6 \pm 18.8$ & $0-94$
\end{tabular}

Source: Research Data, 2019

Note: Mean and standard deviation, median (percentile 25-75), minimum and maximum and \% mean and maximum; SD - standard deviation; Md - Mean.

In Table 3, there is a statistically significant relation of numerical variables with total burden. As a result, it was found that, the higher the age of the caregiver and the length of time they dedicate to the care of the elder, the higher is their burden score; also, the higher is their educational level, the lower the burden.

Still on Table 3, the burden score of caregivers who were the partners of the elderly was significantly higher than those of caregivers who were children, grandchildren, or others. In addition, caregivers who lived with the elderly and used their income to cover the expenses of the elder also presented elevated burden scores.

Table 4 presents the results of the Multivariate Linear Regression to evaluate independent factors associated with burden. The variables that were still associated with burden were: sex of the caregiver ( $p=0.017)$, educational level $(p=0.023)$, length of time devoted to the care of the elderly ( $h r /$ week) $(p=0.045)$ and living with the elderly $(p=0.013)$.

The mean score of female caregivers was 8.2 times higher than that of male ones. Also, for each year of formal education there is a mean decrease of 0.82 in the total burden numbers. In addition, for each extra hour devoted weekly to care for the elderly, there is a mean increase of 0.06 in the burden score. Finally, the score of caregivers who lived with the elderly was 8.73 points above that of caregivers who did not.

The model presented in Table 4 explains $31.7 \%$ of the variability of the total burden score. The variables with the less explanation about this variability were, respectively, caregiver educational level, and caregiver living with the elderly.

Table 3 - Association of the variables with informal caregivers of dependent elderly. Northwest Region, RS, Brazil, 2019

\begin{tabular}{|c|c|c|}
\hline Variables & Total Burden & $\mathbf{p}$ \\
\hline Age of the caregiver* & 0.185 & 0.039 \\
\hline Years of study** & -0.293 & 0.001 \\
\hline How long has the caregiver being caring for the elderly (years) * & 0.042 & 0.646 \\
\hline Age of the elderly (years)* & 0.070 & 0.439 \\
\hline Length of time the caregiver devoted to care for the elderly (hr/week) * & 0.370 & $<0.001$ \\
\hline Length of time others devote to care for the elderly (hr/week) * & -0.129 & 0.151 \\
\hline Elderly's income** & 0.014 & 0.881 \\
\hline Sex of the caregiver ** & & 0.057 \\
\hline Female & $43.5 \pm 19.2$ & \\
\hline Marital status *** & & 0.960 \\
\hline Single or never married & $41.5 \pm 19.2$ & \\
\hline
\end{tabular}


Table 3 - Cont.

\section{Variables}

Married/living with a partner

Widower

Divorced

Relationship ***

Children

Partner

Grandchildren

Siblings

Others

The caregiver lives with the elderly***

Yes

Has aid from someone else to offer care ***

No

The caregiver must spend their own income to cover expenses with the elderly***

Yes

Someone else helps financially to care for the elderly***

Yes
Total Burden

p

$41.3 \pm 18.8$

$41.0 \pm 20.5$

$44.6 \pm 17.2$

0.001

$38.2 \pm 17.9^{\mathrm{a}}$

$60.2 \pm 13.8^{\mathrm{b}}$

$40.6 \pm 31.9^{\mathrm{a}}$

$47.4 \pm 19.1^{\mathrm{ab}}$

$41.4 \pm 12.3^{\mathrm{a}}$

$<0.001$

$47.1 \pm 19.9$

0.093

$45.3 \pm 19.5$

0.001

$48.0 \pm 18.0$

0.565

Source: Research Data, 2019

Notes: ab Equal letters indicate no difference according to a Tukey test with $5 \%$ significance

* Pearson's correlation coefficient

*** Spearman's correlation coefficient

*** Mean \pm Standard Deviation

Table 4 - Multivariate Linear Regression analysis to evaluate factors that were independently associated with total burden. Northeast Region, RS, Brazil, 2019

\begin{tabular}{lccc} 
Variables & $\mathbf{b}(\mathbf{C l} \mathbf{9 5} \%)$ & Beta & $\mathbf{p}$ \\
\hline Age of the caregiver & $-0.09(-0.33$ to 0.15$)$ & -0.076 & 0.441 \\
\hline Sex of the caregiver - Female & $8.20(1.48$ to 14.9$)$ & 0.194 & $\mathbf{0 . 0 1 7}$ \\
\hline Educational level (years) & $-0.82(-1.52$ to -0.12$)$ & -0.230 & $\mathbf{0 . 0 2 3}$ \\
\hline Kinship degree - Partner & $7.48(-3.84$ to 18,8) & 0.127 & 0.193 \\
\hline Length of time the caregiver devotes to care for the elderly (hr/week) & $0.06(0.00$ to 0.11) & 0.177 & $\mathbf{0 . 0 4 5}$ \\
\hline Length of time others devote to care for the elderly (hr/week) & $0.01(-0.07$ to 0.08) & 0.016 & 0.874 \\
\hline The caregiver lives with the elderly & $8.73(1.90$ to 15.6) & 0.227 & $\mathbf{0 . 0 1 3}$ \\
\hline Has aid from someone else to offer care & $-1.68(-9.08$ to 5.73) & -0.043 & 0.654 \\
\hline $\begin{array}{l}\text { The caregiver must spend their own income to cover expenses with } \\
\text { the elderly }\end{array}$ & $4.86(-1.86$ to 11.6) & 0.128 & 0.155 \\
\hline
\end{tabular}

Source: Research Data, 2019. 


\section{DISCUSSION}

The total score of the Caregiver Burden Inventory was above the one found by a national study, carried out in a major urban center, that used the same scale (36.4 \pm 22.8$)$ (11). These different results may be related to the different realities and socio-economic conditions of the elderlies in a large-sized city, making it possible for family caregivers to hire formal caregivers, which may diminish the burden of the caregiver, as well as their access to specialized formal services. On the other hand, the scores were below the study carried out to validate and adapt the scale for use in China, since the mean score found in the sample was $48.8^{(18)}$.

In this study, there was a greater burden in the domain "Time-Dependence Burden". This domain is related to the restrictions to the time the caregiver has to themselves, meaning they need to be constantly attentive to the presence of the elderly, with no rest ${ }^{(17)}$. High scores in this domain may be related to the scarcity of help from other family members, requiring full-time attention from the caregiver. In addition, the dependency of the elderlies with regards to ADLs implies in constant supervision from the caregiver. Similar results were found in a research with Brazilian caregivers in a large-sized urban center ${ }^{(11)}$, in the study that originated the scale in Canada, and in the investigation that validated the scale in Brazil(6,17). These findings indicate that, probably, the dependency of the elderly is similar in the different contexts, whether they are national or international.

The domain with the lowest score was "Emotional Burden". This domain assesses the feelings of embarrassment and shame with regards to the person being cared for, resentment towards that person, and discomfort in the presence of others ${ }^{(17)}$. These feelings may result from unpredictable behavior from the elder, probably related to their cognitive state. Similarly, studies to validate the scale in China ${ }^{(18)}$ and Brazi|(17) found lower emotional burden.

Considering these results, it should be considered that, both in this large-sized city and in the international context, there is a formal support network structured, offering support for carrying out the ADLs. This probably generates relief regarding physical burden and, as a result, lower emotional burden. Other caregivers in the countryside of Brazil do not feel overloaded, but do carry out many activities of care in their houses, among which the ADLs, activities for the maintenance of the house, finance management, and accumulate tasks.

Another research carried out in a major city in the state of Santa Catarina, Brazil, with caregivers linked to the FHS, used the Questionnaire for Assessing the Informal Caregiver Overload (QAICO), finding that most caregivers had emotional burden ${ }^{(9)}$. The different results with regards to this study may be related to the local context, since smaller cities have cultural specificities, such as valuing reciprocity, closer social networks, and better inter-generational relations, favoring a lower emotional burden. For these caregivers in the countryside of RS, emotional support can be a moral value and, as such, be considered a duty in family relations.

In addition, this study has no information on the health condition of the elderly, such as whether they have cognitive deficiencies. This aspect could worsen emotional burden, since it demands specific care with regards to the ability of the elder of resolving daily life problems. Elderlies in this study are believed to have their autonomy preserved, that is, they had the ability to make decisions, positively influencing on the perception of the caregivers with regards to emotional burden.

Regarding the domain "Social Burden", the results of the Canadian investigation in which this scale was created ${ }^{(6)}$ were opposite to those found here, meaning this domain had the greatest score. The "Social Burden" assesses the losses in the relations of the caregivers with other people, and their development in their formal work. It also measures the help caregivers receive or not from other relatives to care for the elderly ${ }^{(17)}$. Caregivers frequently feel devalued and neglected, especially by their relatives, in addition to occasionally having marital disagreements or having to abandon their formal works due to the requirements of caring for the elderly. While caregivers in this study found that offering integral care to the elderly is what overburdens them, the participants of the Canadian study felt overburdened by the lack of emotional support and time for social relations.

Regarding the "Developmental Burden" domain, this study did not find elevated scores, result similar to that of the Brazilian research that used the same scale ${ }^{(11)}$, and to the validation studies of the scale in China ${ }^{(18)}$ and in Brazil ${ }^{(17)}$. The domain assesses the feelings of the caregiver with regards to the time spent caring for the elderly, and whether they abandon their own lives to care for the elderly, and whether they would like to stop being caregivers ${ }^{(17)}$. The caregivers in this study did not feel their social lives were suffering neither felt emotionally exhausted, probably due to their affective link to their relatives, coupled with the satisfaction felt by offering care.

The "Physical Burden" domain did not have high scores, in accordance to the aforementioned Brazilian studies ${ }^{(11,17)}$. It assesses aspects related to the health of the caregiver and to the physical tiredness associated with the process of caring ${ }^{(17)}$. In this aspect, this study expected to find higher scores, since, in the Brazilian context, it is common for families that care for the dependent elderly in their houses to have 
little formal support. On the other hand, this result may indicate better health conditions of the elderly researched, that is, elderly who have smaller dependencies require less support to carry out ADLs, and their caregivers, consequently, are less physically tired.

In this study, the older the caregiver, the higher the burden score. This result was also found in other national and international investigations with informal caregivers of people who were dependent $t^{(7,12-13)}$. These findings can be seen as related to many different contexts, in which there is a high number of younger elderlies caring for older elderlies. In this context, primary healthcare professionals must keep the caretaking family within their sight, especially with regards to the elderlies who are also caregivers, since they also have functional limitations caused by the aging process, as well as by chronic diseases.

Regarding the educational level of the elderlies, the more the years of study, the lower the burden of the caregiver, meaning that the educational level was a protective factor with regards to burden. This association was also found in a study with informal caregivers of elderlies with dementia $(p=0.029)$, in which illiterate caregivers presented with more burden ${ }^{(13)}$. The educational level of caregivers is a factor that influences in their learning ability and in their understanding of the guidance they receive from health professionals, which may influence in the quality of the care offered to the elderly, as well as in the performance of the caregiver with regards to urgent situations. A higher ability from the caregiver in offering the adequate activities in the house, favored by an educational level, is something that can influence in the perception of the caregiver with regards to caregiver burden.

In this study, the more time the caregivers spent caring for the elderly, the higher were their burden scores $(p<0.001)$. Similarly a study with informal caregivers of elderly with dementia, which analyzed the relation between the burden of caregivers and their sociodemographic and clinical profile in an Elderly Healthcare Center in Rio de Janeiro/Brazil, found that the higher the median of hours spent caring for the elderly, the higher the burden of the caregivers ${ }^{(10)}$.

Corroborating these results, another research carried out in the Home Healthcare Service in the city of Goiânia/Brazil, also a major city, with informal and formal healthcare, found that the highest burden levels were associated to the fact that the caregiver did not have any week days off ( $p=0.002$ ) (19). Reiterating this result, a study that analyzed the relation between the quality of life of informal caregivers and their burden in the offering of healthcare to elderlies living in Portugal, found that the caregivers with the highest burden and the lowest quality of life were those who spent the most hours each day caring for the elderly $y^{(7)}$.
Therefore, the time dedicated to caring for the elderly can increase the levels of burden tension, since little time available means less time for self-care, less social networking, and less opportunities for experiences and leisure with others. Still, these factors become worse when the caregiver take care for the elderly with no help from other relatives, being the only one to carry out the activities, full-time, meaning they are required to offer constant surveillance, and even their moments of rest are planned with regards to the elderly. Therefore, regardless of context, be it international or in Brazilian large-sized cities, the time dedicated to the elderly is a factor that predisposes to burden, corroborating this study.

The caregivers who were companions of the elderly presented with an burden higher than that of the others. A research carried out in the countryside of the state of São Paulo(12) found a different result, according to which proximity and affective relations between the relative caregiver and the elderly minimize negative feelings from the caring process. The finding of this study may be related to the fact that many partners, in addition to caring for their partner full-time, since they live with the person being cared for, also contributed financially the person receiving care. In addition, the advanced age of the partners must also be considered, as well as the health problems that may emerge as a result from caring for the other ${ }^{(15)}$.

An important aspect that was related to the burden of the caregiver was living with the elderly, since it also took place in another investigation ${ }^{(20)}$. In this study, families were the main responsible for the care of the elderly, which may be related to cultural factors and to the scarcity of long-term caregiver support services in small towns. Considering that, as the functional capacity of elderly decreases and they increasingly need aid to carry out ADLs, new demands of care for the caregiver are established, and the unceasing exercise of this activity influences in the increased burden ${ }^{(10-11)}$. Additionally, caring for the elderly, generally, is thought to be an addition to other daily life activities, which may lead to an even greater burden.

It should also be considered that some caregivers did not have the help of others in offering care and did it on their own. The little support in the development of the healthcare activities required by the dependent elderly, associated with the scarcity of formal support networks also may favor the increase of the burden. As another study highlighted, there are too many users in the higher complexity levels, due to the lack of care in primary healthcare ${ }^{(2)}$.

Additionally, most caregivers in this study used their own income to cover the expenses of the elderly. This assistance takes many forms, including help in domestic activities, in daily life activities, in expenses with medication and food. 
As another study highlighted, the socioeconomic level is a factor that may negatively influence caregivers, leading to financial burden ${ }^{(7)}$. In addition, caregivers are understood to have financial trouble due to the requirements of care, which in most cases prevent them from having an external work. Still, they need to acquire materials to adequately care for the elderly. Considering this context in which the possibility to earn an income is limited and there are high costs associated with keeping a dependent elderly in one's house, the social lives and leisure of caregivers is believed to be negatively affected, which influences in the burden.

The results of this study indicate the need to offer support to the caregiver, aiming to diminish the burden related to the activities that are inherent to daily healthcare. As a result, healthcare to the elderly, the family and the caregiver should be organized in a way that is articulated and integrated in the healthcare network. Healthcare must be cross-sectional, with the help of the elaboration of lines of care which are focused on the promotion of health, and based on the early identification of factors that predispose or increase the risk of deterioration or burden ${ }^{(2)}$.

This is a challenge for health services and, in the case of this emerging group (elderlies and caregivers) the access to this network mostly takes place in an advanced stage, in which the gateway to the system ends up being the emergency room of a hospital, making it more difficult to solve the problem and offer continuous, family-focused healthcare(2). This study also raises questions about the role of the State, in the context of the Brazilian Health System (SUS), with regards to organizing a formal support network to offer care for families with dependent elderlies and their caregivers.

\section{- CONCLUSION}

In this study, the burden of caregivers had statistically significant relations to their age, educational level, the time they devoted to the elderly, their kinship degree, living with the elderly, and using their own income to cover the expenses of the elderly. The results found are challenging, since they indicate how important it is for healthcare to be cross-sectional, that is, with interaction between the levels of the health system and family caregivers. The demands of a caregiver should be shared, with the help of other support networks, such as support groups in primary healthcare.

This study will contribute, with regards to the practice of nursing, for the management and organization of primary healthcare services, as it identifies factors related to the burden of caregivers. This makes it possible to implement actions aimed at minimizing the impact of caring for an elderly who is a dependent. In addition, it may contribute for the elaboration of health policies targeted at the informal caregiver, as well as in the structuring of a formal support network in the context of the Brazilian Health System (SUS).

This study has some limitations. One of them is the fact that no causal relation between results can be confirmed. In addition, the lack of a financial burden domain in the scale makes it impossible to test this type of burden in the caregivers, meaning a comparison with other studies that assess this factor is impossible. In addition, the functional capacity and the health situation of the elderlies could contribute with the analysis of the burden of caregivers. Also, the caregivers of the elderlies belong to a specific region of the country with features that are distinctive from other regions. Other researches are suggested to identify factors related to the burden of caregivers in other contexts, addressing these aspects in a cross-sectional approach.

\section{DEFERENCES}

1. Lima-Costa MF, Peixoto SV, Malta DC, Szwarcwald CL, Mambrini JVM. Informal and paid care for Brazilian older adults (National Health Survey, 2013). Rev Saúde Pública. 2017:51(Supl 1):6s. doi: https://doi.org/10.1590/s15188787.2017051000013

2. Veras R. Care pathway for the elderly: detailing the model. Rev Bras Geriatr Gerontol. 2016;19(6):887-905. doi: https://doi.org/10.1590/1981-2256201 6019.160205

3. Veras RP, Oliveira M. Aging in Brazil: the building of a healthcare model. Ciênc Saúde Coletiva. 2018;23(6):1929-36. doi: https://doi.org/10.1590/141381232018236.04722018

4. Diniz MAA, Melo BRS, Neri KH, Casemiro FG, Figueiredo LC, Gaioli CCLO, et al. Comparative study between formal and informal caregivers of older adults. Ciênc Saúde Coletiva. 2018:23(11):3789-98. doi: https://doi.org/10.1590/1413812320182311.16932016

5. Delalibera M, Presa J, Barbosa A, Leal I. Burden of caregiving and its repercussions on caregivers of end-of-life patients: a systematic review of the literature. Ciênc Saúde Coletiva. 2015;20(9):2731-47. doi: https://doi.org/10.1590/141381232015209.09562014

6. NovaK M, Guest C. Application of a Multidimensional Caregiver Burden Inventory. Gerontologist. 1989;29(6):798-803. doi: http://dx.doi.org/10.1093/ geront/29.6.798

7. Duarte A, Joaquim N, Lapa F, Nunes C. Quality of life and burden of informal caregivers of elderly patients of home care assistance in the Algarve. SaBios: Rev Saúde Biol. 2017 [citado 2019 abr 12];11(3):12-26. Disponível em:http://revista2.grupointegrado.br/revista/index.php/sabios2/article/ view/1661/966

8. Prevo L, KlaasJan H, Linssen E, Kremers $S$, Crutzen $R$, Schneider $F$. Population characteristics and needs of informal caregivers associated with the risk of perceiving a high burden: a cross-sectional study. Inquiry. 2018:55:46958018775570. doi: https://doi.org/10.1177/0046958018775570

9. Souza LR, Hanus JS, Dela Libera LB, Silva VM, Mangilli EM, Simões PW et al. [Overload in care, stress and impact on the quality of life of surveyed caregivers assisted in primary care]. Cad Saúde Coletiva. 2015;23(2):140-9. Portuguese. doi: https://doi.org/10.1590/1414-462X201500020063 
10. Leite BS, Camacho ACLF, Joaquim FL, Gurgel JL, Lima TR, Queiroz RS. Vulnerability of caregivers of the elderly with dementia: a cross-sectional descriptive study. Rev Bras Enferm. 2017 [cited 2019 Apr 12];70(4):682-8. Available from: http://www.scielo.br/scielo.php?script=sci_arttext\&pid $=$ S0034-71672017000400682

11. Aires M, Mocellin D, Fengler FL, Rosset I, Santos NO, Machado DO, et al. Association between filial responsibility when caring for parents and the caregivers overload. Rev Bras Enferm. 2017;70(4):767-74. doi: https://doi. org/10.1590/0034-7167-2017-0133

12. Jesus ITM, Orlandi AAS, Zazzetta MS. Burden, profile and care: caregivers of socially vulnerable elderly persons. Rev Bras Geriatr Gerontol. 2018;21(2):194204. doi: https://doi.org/10.1590/1981-22562018021.170155

13. Santos-Orlandi AA, Brito TRP, Ottaviani AC, Rossetti ES, Zazzetta MS, Gratão ACM, et al. Profile of older adults caring for other older adults in contexts of high social vulnerability. Esc Anna Nery. 2017 [cited 2019 Apr 12];21(1):e20170013. Available from: http://www.scielo.br/scielo. php?pid=S1414-81452017000100213\&script=sci_arttext\&tlng=en

14. Brigola AG, Luchesi BM, Rossetti ES, Mioshi E, Inouye K, Pavarini SCI. Health profile of family caregivers of the elderly and its association with variables of care: a rural study. Rev Bras Geriatr Gerontol. 2017;20(3):409-20. doi: https:// doi.org/10.1590/1981-22562017020.160202
15. Gomes NP, Pedreira LC, Gomes NP, Fonseca EOS, Reis LA, Santos AA. Healthrelated consequences of caring for dependent relatives in older adult caregivers. Rev Esc Enferm USP. 2019;53:e03446. doi: https://doi.org/10.1590/S1980$220 \times 2018002303446$

16. Instituto Brasileiro de Geografia e Estatística [Internet]. Rio de Janeiro: IBGE; c2010-2019 [citado 2019 fev 3]. Sinopse do censo demográfico 2010 Rio Grande do Sul: população residente, por grupos de idade, segundo os municípios e o sexo; [aprox. 1 tela]. Disponível em: https://censo2010.ibge.gov. $\mathrm{br} /$ sinopse/index. . $h \mathrm{p} ? \mathrm{uf}=43 \& \mathrm{dad}$ os $=26$

17. Valer DB, Aires M, Fengler FL, Paskulin LMG. Adaptation and validation of the Caregiver Burden Inventory for use with caregivers of elderly individuals. Rev Latino-Am Enfermagem. 2015;23(1):130-8. doi: https://doi. org/10.1590/0104-1169.3357.2534

18. Chou, KR, Jiann-Chyun L, Chu H. The reliability and validity of the Chinese version of the caregiver burden inventory. Nurs Res. 2002;51(5):324-331. doi: https://doi.org/10.1097/00006199-200209000-00009

19. Guerra HS, Almeida NAM, Souza MR, Minamisava R, Tobias GC. Quality of life of caregivers at a home care service. Rev Enferm UFPE on line. 2017 [cited 2019 Apr 2];11(Supl. 1):254-63. Available from: https://periodicos.ufpe.br/revistas/ revistaenfermagem/article/view/11903

20. Mehta KK, Leng TL. Experiences of formal and informal caregivers of older persons in Singapore. J Cross Cult Gerontol. 2017;32(3):373-85. doi: https:// doi.org/10.1007/s10823-017-9329-1

\section{- Corresponding author:}

Marines Aires

E-mail.maires@uri.edu.br

\section{Associate editors:}

Ana Karina Silva da Rocha Tanaka Cecília Helena Glanzner

\section{Editor-in-chief:}

Maria da Graça Oliveira Crossetti 